\title{
Novel adult neural stem cell line independent from exogenous cytokines
}

\author{
Aljoscha Kaus*†, Darius Widera ${ }^{\dagger}$, Philipp Tropberger, Barabara Kaltschmidt \\ and Christian Kaltschmidt
}

Address: Institut für Neurobiochemie, Universität Witten/Herdecke, Witten, Germany

* Corresponding author †Equal contributors

\author{
from Annual Meeting of the Study Group Neurochemistry. International Conference of the Gesellschaft für Biochemie und Molekularbiologie 2006 (GBM \\ 2006): Molecular pathways in health and disease of the nervous system \\ Witten, Germany. 28-30 September 2006 \\ Published: 23 March 2007 \\ BMC Neuroscience 2007, 8(Suppl I):P36 doi:10.1 186/I47I-2202-8-SI-P36
}

(C) 2007 Kaus et al; licensee BioMed Central Ltd.

The environmental and genetic signals regulating progressive lineage elaboration in the mammalian brain are yet poorly understood. Moreover, developmental characteristics and profiles of the central nervous system (CNS) stem cells regarding mechanisms of their nearly unlimited selfrenewal, lineage restriction, and cellular maturation remain fragmentary. Those properties are characteristical for cancerous cells as well.

We differentiated neural stem cells (NSCs) in absense of cytokines on poly-d-lysin/laminin coated substrates and harvested non-adherent suspension cells. These cells then were cultured without cytokines. Since they were maintainable in culture without exogeneous cytokines, we examined whether they still beared stemness characteristics.

Typing of the re-formated clusters by immunofluorescence as well as RT-PCR for expression of stemness markers, such as nestin, musashi, notch 1 and notch 2 yielded a profile analogous to neural stem cells.

Moreover, the cells exerted a proliferative doubling time of about $26 \mathrm{~h}$ and migration activity in response to MCP1. Though western blot analysis did not feature detectable amounts of the Cytokine bFGF (FGF-2), we termed this culture exogene Cytokine independent Neural Stem Cells (CiNSC). Interestingly, those CiNSCs showed twofold higher basal NF- $\mathrm{KB}$ activity than NSCs from the subventricular zone. Nine single cell derived clones were obtained and cultured for at least 30 passages.
Since most of the described tumor cells showed a high constitutive NF- $\kappa B$ activity, these results provide potential common denominator between cancer cells and stem cells. In particular CiNSCs may provide a potent tool in cancer research, as their exogene cytokine independent proliferation presumes cancerous properties. 